\title{
miR-15a-5p acts as an oncogene in renal cell carcinoma
}

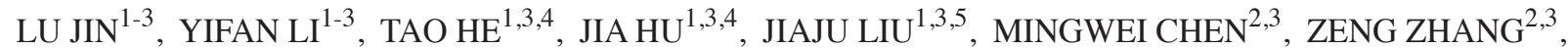 \\ YAOTING GUI $^{3}$, XIANGMING MAO ${ }^{1,3}$, SHANGQI YANG ${ }^{1,3}$ and YONGQING LAI ${ }^{1,3}$ \\ ${ }^{1}$ Department of Urology, Peking University Shenzhen Hospital, Shenzhen, Guangdong 518036; ${ }^{2}$ Anhui Medical University, \\ Hefei, Anhui 230032; ${ }^{3}$ The Guangdong and Shenzhen Key Laboratory of Male Reproductive Medicine and Genetics, \\ Peking University Shenzhen Hospital, Institute of Urology of Shenzhen PKU-HKUST Medical Center, Shenzhen, \\ Guangdong 518036; ${ }^{4}$ Department of Clinical Medicine, Guangzhou Medical University, Guangzhou, Guangdong 511436; \\ ${ }^{5}$ Department of Clinical Medicine, Shantou University Medical College, Shantou, Guangdong 515041, P.R. China
}

Received September 30, 2015; Accepted October 7, 2016

DOI: $10.3892 / \mathrm{mmr} .2017 .6121$

\begin{abstract}
RNAs have been reported to be involved in multiple cellular processes and the tumorigenesis of various cancers. miR-15a-5p (also termed miR-15a) has previously been determined to be upregulated in renal cell carcinoma (RCC) by microarray profile. However, the expression and function of miR-15a-5p in $\mathrm{RCC}$ remain to be validated. In the present study, reverse transcription-quantitative polymerase chain reaction (RT-qPCR) was performed to detect the expression levels of miR-15a-5p in RCC tissues and cells. The expression level of miR-15a-5p was upregulated or downregulated by transfecting synthesized miR-15a-5p mimics or inhibitors. The MTT assay, CCK-8 assay, Transwell assay, wound healing assay, Hoechest 33342 staining and flow cytometry were conducted to investigate the role of miR-15a-5p in RCC. The results of the RT-qPCR demonstrated that miR-15a-5p was upregulated in RCC tissues and ACHN, 786-O and 769P RCC cells compared with paired normal tissues and HEK-293T cells. miR-15a-5p was observed to be associated with RCC cell proliferation, migration, invasion and apoptosis. The results demonstrated that miR-15a-5p may be important as a tumor promoter in RCC. To the best of our knowledge, the present study is the first to describe miR-15a-5p as a tumor promoter in RCC. Further research will be performed to investigate the underlying signaling pathway of miR-15a-5p and the potential role of miR-15a-5p as a biomarker for early detection, prognosis prediction and a therapeutic target of RCC.
\end{abstract}

Correspondence to: Professor Yongqing Lai or Professor Shangqi Yang, Department of Urology, Peking University Shenzhen Hospital, 1120 Lianhua Road, Shenzhen, Guangdong 518036, P.R. China E-mail: yqlord@163.com

E-mail: yangshangqi88@aliyun.com

Key words: microRNA, miR-15a-5p, renal cell carcinoma, oncogene

\section{Introduction}

In recent years, microRNAs (miRNA) have been considered important molecules that are important in the regulation of tumorigenesis (1). miRNAs are a type of small non-coding RNAs 20 nucleotides in length $(2,3)$. Previous studies have reported that miRNAs exert an effect on different cell processes, including cell differentiation, migration, growth, proliferation, apoptosis and metabolism $(4,5)$. miRNAs exert these effects by binding with the 3'-untranslated region of its target mRNA $(6,7)$. Increasing evidence demonstrates that miRNAs are directly involved in the pathogenesis of various tumors $(6,8)$. In addition, miRNAs have become novel biomarkers for the diagnosis or therapy of diseases, including cancer, heart disease and diabetes $(7,9)$.

Renal cell carcinoma (RCC) accounts for $\sim 3 \%$ of adult malignancies and represents $90 \%$ of renal tumors with the highest rate of recurrence and mortality among the malignances of the urinary system $(10,11)$. In addition, $30 \%$ of patients with RCC continued to present with metastases (12), and the prognosis of patients with RCC remains poor. However, the underlying mechanism of RCC requires further elucidation. Thus, it is important to increase the understanding of tumorigenesis and development of RCC, and develop a biomarker for RCC diagnosis at early stages or as a molecular targeted therapy.

miR-15a-5p, located at chromosome 13q14 (13), has been demonstrated to be dysregulated in a number of tumors, such as pancreatic cancer (14), chronic lymphocytic leukemia (15), and pituitary (16). However, to the best of our knowledge, there has been no research into miR-15a-5p on RCC. Thus, the present study aimed to detect the expression of miR-15a-5p in RCC tissues and cells and to determine the function of miR-15a-5p on cell proliferation, migration, invasion and apoptosis.

\section{Materials and methods}

Sample collection. A total of 27 paired tissues were collected from Guangdong province (China; between January 2014 and January 2015), which consisted of renal cell carcinoma tissues and adjacent normal renal tissues. Written informed consent 
was obtained from all patients. Collection and use of the samples were reviewed and approved by the ethics committee Peking University Shenzhen Hospital. While the tissues were dissected, they were immersed in RNAlater (Qiagen $\mathrm{GmbH}$, Hilden, Germany) for $30 \mathrm{~min}$, then the tissues were stored at $-80^{\circ} \mathrm{C}$ for further use, and a pair of tissues included RCC and adjacent normal tissues $2 \mathrm{~cm}$ away from visible RCC lesions. The tissues collected were reviewed and classified by hematoxylin and eosin staining. The clinical and pathological characteristics of the patients are presented in Table I.

Cell culture. 293-T human embryo kidney cells and 786-O and ACHN RCC cell lines were used in the present study. Cells were cultured in a humidified incubator containing $5 \% \mathrm{CO}_{2}$ at $37^{\circ} \mathrm{C}$ in Dulbecco's modified Eagle's medium (DMEM; Gibco; Thermo Fisher Scientific, Inc., Waltham, MA, USA) with $10 \%$ fetal bovine serum (FBS; Gibco; Thermo Fisher Scientific, Inc.), $1 \%$ antibiotics $(100 \mu \mathrm{l} / \mathrm{ml}$ penicillin and $100 \mathrm{mg} / \mathrm{ml}$ streptomycin sulfates) and $1 \%$ glutamine.

RNA extraction, cDNA synthesis and quantitative polymerase chain reaction ( $q P C R)$. Total RNA was extracted from the samples and cells by TRIzol (Invitrogen; Thermo Fisher Scientific, Inc.) and purified with the RNeasy Maxi kit (Qiagen $\mathrm{GmbH}$ ) according to the manufacturer's protocols. The concentration of RNA was measured on a NanoDrop 2000/2000c (Thermo Fisher Scientific, Inc.). RT-qPCR was performed to synthesize the cDNA, $1 \mu \mathrm{g}$ total RNA of each sample was used for reverse transcription using miScript Reverse Transcription kit (Qiagen $\mathrm{GmbH}$ ) following the manufacturer's protocols. qPCR was performed to detect the expression level of miR-15a-5p with miScript SYBR ${ }^{\circledR}$ Green PCR kit (Qiagen GmbH) on the Roche Lightcycler 480 Real-Time PCR system (Roche Diagnostics, Basel, Switzerland) according to the manufacturer's protocols. U6 served as the internal control. The sequences of the primers were as follows: miR-15a-5p, forward 5'-TAGCAGCAC ATAATGGTTTGTG-3', and universal primer was used as the reverse primer (provided by the miScript SYBR ${ }^{\circledR}$ Green PCR kit); U6, forward 5'-CTCGCTTCGGCAGCACA-3' and reverse 5'-ACGCTTCACGAATTTGCGT-3'. The thermocycling conditions were as follows: $95^{\circ} \mathrm{C}$ for $1 \mathrm{~min}$, then 40 cycles of $95^{\circ} \mathrm{C}$ for $10 \mathrm{sec}, 55^{\circ} \mathrm{C}$ for $30 \mathrm{sec}$ and $70^{\circ} \mathrm{C}$ for $30 \mathrm{sec}$. The expression levels of miR-15a-5p in tissues and cells were analyzed with $2^{-\Delta \Delta \mathrm{Cq}}$ method (17).

Cell transfection. The expression level of miR-15a-5p in 786-O and ACHN cells was upregulated by transfecting the synthesized miR-15a-5p mimics and downregulated by transfecting the synthesized miR-15a-5p inhibitor using Lipofectamine 2000 (Invitrogen; Thermo Fisher Scientific, Inc.), which was mixed in the Opti-MEM ${ }^{\circledR}$ I Reduced Serum Medium (Gibco; Thermo Fisher Scientific, Inc.) following the manufacturer's protocols. RT-qPCR was performed (as described above) to observe the changes in miR-15a-5p expression. The sequences are presented in Table II.

Wound healing assay. The wound healing assay was performed to assess the cell migration ability of 786-O and ACHN cells in vitro. In the wound healing assay, $\sim 3 \times 10^{5}$ cells
Table I. Clinicopathological features in RCC patients.

\begin{tabular}{lc} 
Characteristic & Number of ca \\
\hline Mean age range (years) & $50(25-70)$ \\
Sexual distinction & $18 / 10$ \\
Male/female & \\
Histological type & $25 / 3$ \\
Clear cell/papillary & \\
pT-stage & $16 / 10 / 2$ \\
T1/T2/T3+T4 & \\
Fuhrman grade & $8 / 14 / 4 / 2$ \\
I/II/III/IV & \\
AJCC clinical stages & $16 / 10 / 2$ \\
I/II/III+IV &
\end{tabular}

pT, primary tumor; AJCC, American Joint Committee on Cancer; $\mathrm{RCC}$, renal cell cancer.

Table II. Sequences of the siRNAs.

\begin{tabular}{ll}
\hline siRNA & \multicolumn{1}{c}{ Sequence (5'-3') } \\
\hline miR-15a mimic & S: UAGCAGCACAUAAUGGUUUGUG \\
& A:CAAACCAUUAUGUGCUGCUAUU \\
Negative control & S: UUCUCCGAACGUGUCACGUTT \\
& A:ACGUGACACGUUCGGAGAATT \\
miR-15a inhibitor & CACAAACCAUUAUGUGCUGCUA \\
Inhibitor NC & CAGUACUUUUGUGUAGUACAA \\
\hline
\end{tabular}

miR, microRNA; NC, negative control; siRNA, small interfering RNA; S, sense; A, antisense.

were seeded in every well of the 12 -well plate, and $24 \mathrm{~h}$ later the cells were transfected with 40 pmol of miR-15a-5p mimics, inhibitors, negative control or inhibitor negative control using Lipofectamine ${ }^{\circledR}$ 2000. A vertical horizontal line was scratched with a sterile $200 \mu \mathrm{l}$ pipette tip after $6 \mathrm{~h}$ of transfection. To remove the floating cells the cells were rinsed with phosphate-buffered saline (PBS) and then cultured at $37^{\circ} \mathrm{C}$ in a humidified chamber containing $5 \% \mathrm{CO}_{2}$. A digital camera system was used to capture images of the scratches at 0,12 and $24 \mathrm{~h}$ after making the scratch. The experiments were performed in triplicate and repeated at least 3 times.

Transwell assay. A Transwell assay was performed to assess the cell migration and invasion ability of 786-O and ACHN cells in vitro. Transwell chamber inserts (BD Biosciences, Franklin Lakes, NJ, USA) with or without Matrigel (for invasion) were used in the assay according to the manufacturer's protocol. The transfected cells were seeded in the upper chamber of the insert at a density of $1 \times 10^{4}$ cells in $200 \mu$ l serum-free DMEM. The bottom of the inserts contained DMEM with $10 \%$ FBS. The 786-O cells were allowed to migrate for $36 \mathrm{~h}$ and invade for $48 \mathrm{~h}$. The ACHN cells were allowed to migrate for $36 \mathrm{~h}$ 

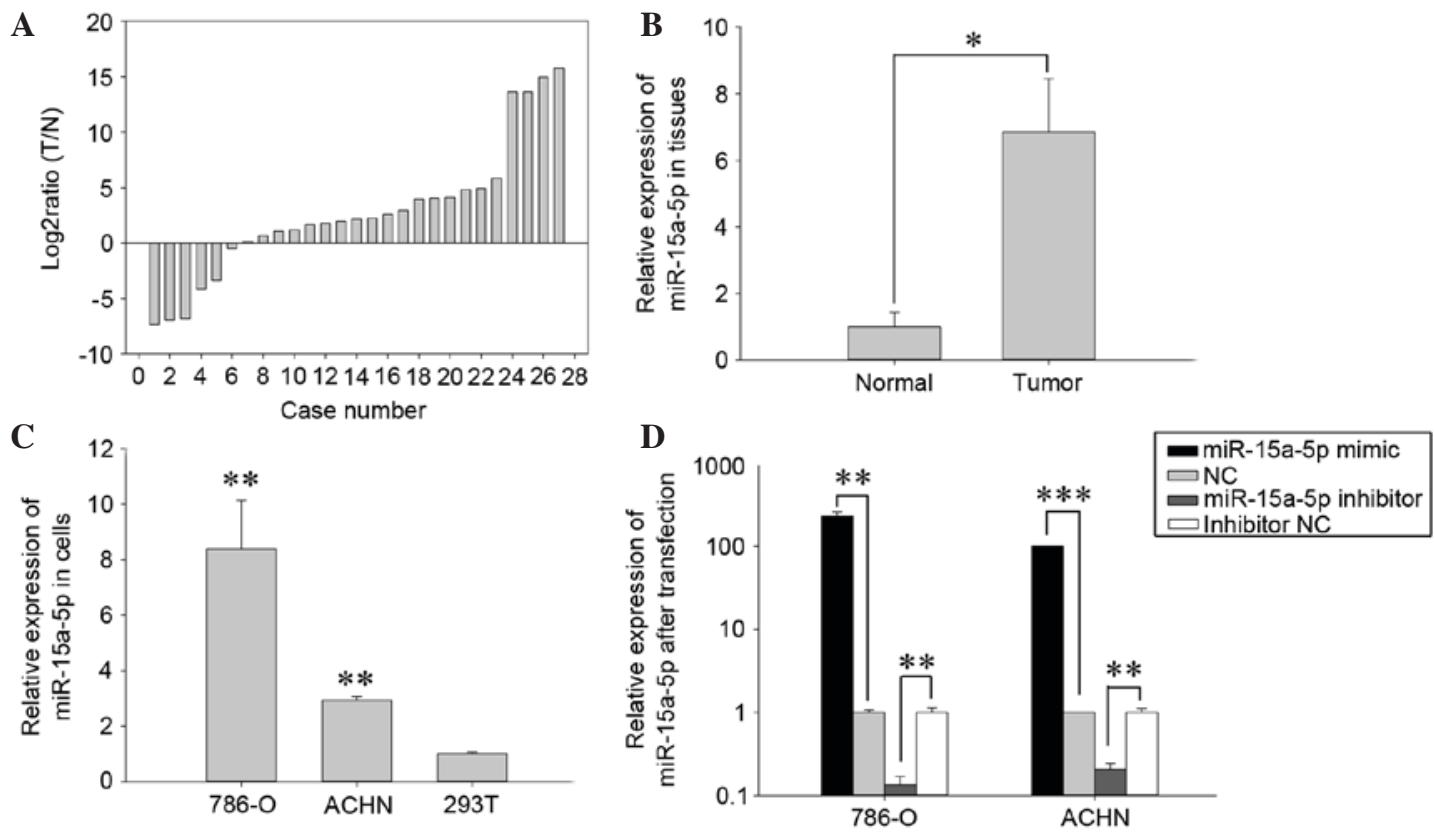

Figure 1. Expression levels of miR-15a-5p in 28 paired tissue samples and cell lines. (A) Log2 ratios of miR-15a-5p expression in 28 paired $\mathrm{T}$ and $\mathrm{N}$ tissues (B) The relative expression of miR-15a-5p in tumor and normal tissues. (C) The relative expression of miR-15a-5p in RCC cell lines. (D) The expression of miR-15a-5p following transfection in 786-O and ACHN cells. ${ }^{*} \mathrm{P}<0.05,{ }^{* *} \mathrm{P}<0.01,{ }^{* * * *} \mathrm{P}<0.001$. miR, microRNA; T, RCC tissues; $\mathrm{N}$, normal kidney tissues; $\mathrm{NC}$, negative control.

and invade for $60 \mathrm{~h}$. The cells that had migrated or invaded to the bottom of the inserts were stained with crystal violet and counted using a light microscope.

MTT assay. A 3-(4, 5-dimethylthiazol-2-yl)-2,5-diphenyltetrazolium bromide (MTT) assay was performed to assess the cell proliferation ability of 786-O and ACHN cells in vitro. In each well of a 96-well plate, 5,000 cells were seeded and then transfected with 5 pmol miR-15a-5p mimics, inhibitors, NC or inhibitor NC. MTT ( $20 \mu \mathrm{l}, 5 \mathrm{mg} / \mathrm{ml}$; Sigma-Aldrich; Merck Millipore, Darmstadt, Germany) was added into the wells and detected at $0,24,4872 \mathrm{~h}$ post-transfection. The 96-well plate was incubated at $37^{\circ} \mathrm{C}$ in a humidified incubator containing $5 \% \mathrm{CO}_{2}$ for $6 \mathrm{~h}$. Subsequently, the mixed DMEM would be replaced by $150 \mu \mathrm{l}$ dimethyl sulfoxide (Sigma-Aldrich; Merck Millipore). Subsequently, the 96-well plate was agitated for $30 \mathrm{~min}$ at room temperature and the optical density (OD) of each well was measured by an ELISA microplate reader (Bio-Rad Laboratories, Inc., Hercules, CA, USA) at a wavelength of $490 \mathrm{~nm}$.

Cell Counting Kit-8 (CCK-8) assay. Cell proliferation of 786-O and ACHN cells was also detected using CCK-8 (Beyotime Institute of Biotechnology, Haimen, China) following the manufacturer's protocols. In each well of the 96-well plate $\sim 5,000$ cells were seeded and $24 \mathrm{~h}$ later the cells were transfected with 5 pmol miR-15a-5p mimics, inhibitors, NC or inhibitor NC. At 0, 24, 48 and $72 \mathrm{~h}$ after transfection, the OD of each well was measured using the ELISA microplate reader (Bio-Rad Laboratories, Inc.) at a wavelength of $490 \mathrm{~nm}$.

Flow cytometry assay for apoptosis. The apoptotic rates of 786-O and ACHN cells in vitro were measured using a flow cytometry assay. Approximately $3 \times 10^{5}$ cells were seeded in each well of a 6-well plate and then transfected with 200 pmol miR-15a-5p mimics, inhibitors, NC or inhibitor NC. At $48 \mathrm{~h}$ post-transfection, all cells were harvested and washed with cold PBS twice. The cells were subsequently resuspended in $100 \mu \mathrm{l} 1 \mathrm{X}$ binding buffer and $5 \mu \mathrm{l}$ Annexin V-fluorescein isothiocyanate (Invitrogen; Thermo Fisher Scientific, Inc.) and $5 \mu \mathrm{l}$ propidium iodide (Invitrogen; Thermo Fisher Scientific, Inc.) were added to each cell suspension. After $15 \mathrm{~min}$ of staining in a dark place at room temperature, $400 \mu \mathrm{l}$ binding buffer was added to each tube. Flow cytometry (EPICS, Xl-4; Beckman Coulter, Inc., Brea, CA, USA) was used to analyze the apoptotic rate.

Hoechest 33342 staining assay. ACHN and 786-O cells were cultured in six-well plates. Following transfection with miR-15a-5p mimics, inhibitors, NC or inhibitor NC for $48 \mathrm{~h}$, cells were washed with PBS and stained with Hoechst 33342 (5 $\mu \mathrm{g} / \mathrm{ml}$; Thermo Fisher Scientific, Inc.) for $10 \mathrm{~min}$. Images of the cells were acquired with the immunofluorescent microscope after washing 2 times in PBS.

Statistical analysis. Paired t-tests were used to compare the expression levels of miR-15a-5p in matched tumor/normal tissues and different cells. Student's t-test was used to analyze assays for characterizing phenotypes of cells. All the statistical analysis was conducted using SPSS 19.0 (IBM SPSS, Armonk, NY, USA). Data are presented as the mean \pm standard error. $\mathrm{P}<0.05$ was considered to indicate a statistically significant difference.

\section{Results}

miR-15a-5p was upregulated in RCC tissues and cell lines. To determine the expression level of miR-15a-5p, qPCR was 
A

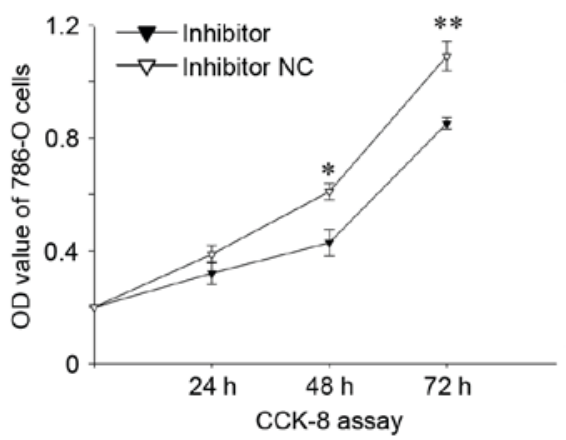

C

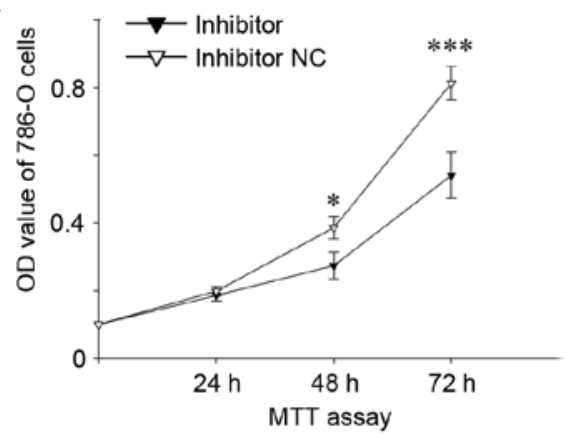

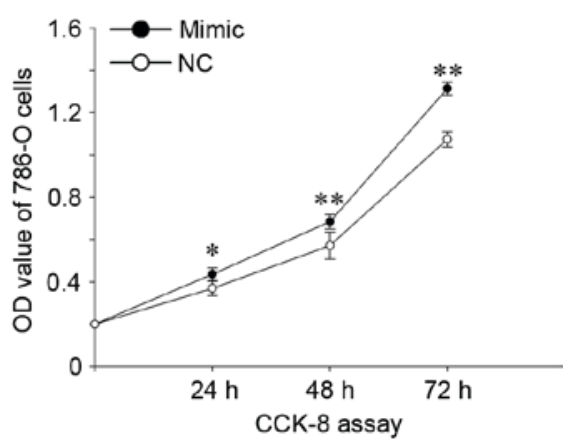

D

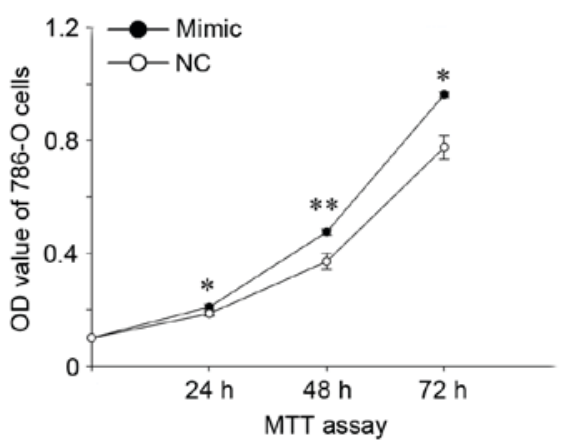

Figure 2. Cell proliferation assay of 786-O cells. (A and B) CCK-8 and (C and D) MTT assay were used to assess the cell proliferation of 786-O cells transfected with (A and C) miR-15a-5p inhibitor or inhibitor NC and (B and D) miR-15a-5p mimic or NC. ${ }^{*} \mathrm{P}<0.05,{ }^{* *} \mathrm{P}<0.01,{ }^{* * * *} \mathrm{P}<0.001$ vs. NC. NC, negative control; OD, optical density; CCK-8, Cell Counting Kit 8.

performed in 28 paired $\mathrm{RCC}$ tissues and adjacent normal tissues. Relative expression of miR-15a-5p [Log2 (T/N)] was presented in Fig. 1A. The present study demonstrated that the expression of miR-15a-5p in RCC tissues was significantly higher than adjacent normal tissues $(\mathrm{P}<0.05$; Fig. 1B). The expression levels of miR-15a-5p in the 786-O and ACHN RCC cell lines and HEK-293T normal human embryo kidney cell line were also detected and the results indicated that expression of miR-15a-5p was significantly higher in 786-O and ACHN $(\mathrm{P}<0.01)$ compared with $293 \mathrm{~T}$ cells, which is consistent with the expression pattern of miR-15a-5p in RCC tissues (Fig. 1C).

Validation of cell transfection efficiency. To determine whether the expression level of miR-15a-5p was changed by transfecting miR-15a-5p mimic or inhibitor, RT-qPCR was performed. The results indicated that miR-15a-5p was downregulated by $79.22 \%$ in $\mathrm{ACHN}$ and $86.54 \%$ in $786-\mathrm{O}$ following transfection with miR-15a-5p inhibitor compared with the inhibitor $\mathrm{NC}(\mathrm{P}<0.01)$. In addition, the expression levels of miR-15a-5p were 228.67 times higher $(786-\mathrm{O}$ cells, $\mathrm{P}<0.05)$ and 100.08 times higher $(\mathrm{ACHN}$ cells, $\mathrm{P}<0.001)$ in cells transfected with miR-15a-5p mimics compared with. negative control (NC) as presented in Fig. 1D.

miR-15a-5p promoted cell proliferation. Cell proliferation determined by the MTT assay and the CCK- 8 assay in vitro. The results of the MTT and CCK- 8 assays suggested that upregulation of miR-15a-5p promoted cell proliferation while downregulation of miR-15a-5p inhibited cell proliferation. The cell proliferation of 786-O (Fig. 2) and ACHN cells (Fig. 3) was reduced by $17.38,29.73 \%(\mathrm{P}<0.05), 21.85 \%(\mathrm{P}<0.01 ;$ Fig. $2 \mathrm{~A})$ and $8.31,8.13 \%(\mathrm{P}<0.01), 8.87 \%(\mathrm{P}<0.05$; Fig. $3 \mathrm{~A})$ in $\mathrm{CCK}-8$, 6.30, 29.04\% $(\mathrm{P}<0.05), 33.44 \%(\mathrm{P}<0.001$; Fig. $2 \mathrm{C})$ and $5.47 \%$
$(\mathrm{P}<0.05), 15.61 \%(\mathrm{P}<0.01), 17.80 \%(\mathrm{P}<0.001$; Fig. $3 \mathrm{C})$ as determined by the MTT assay following transfection with an miR-15a-5p inhibitor at 24, 48 and $72 \mathrm{~h}$ compared with those transfected with inhibitor NC, respectively. The cell proliferation of 786-O and ACHN cells was upregulated by $18.19 \%(\mathrm{P}<0.05), 19.78 \%(\mathrm{P}<0.01), 22.32 \%$ ( $\mathrm{P}<0.01$; Fig. $2 \mathrm{~B})$ and $16.58 \%(\mathrm{P}<0.05), 9.69 \%(\mathrm{P}<0.05), 19.92 \%(\mathrm{P}<0.05$; Fig. 3B) in CCK-8, $12.52 \%(\mathrm{P}<0.05), 28.12 \%(\mathrm{P}<0.01), 24.09 \%$ $(\mathrm{P}<0.05$; Fig. 2D) and $8.03 \%(\mathrm{P}<0.05), 13.51 \%(\mathrm{P}<0.01)$, $24.17 \%(\mathrm{P}<0.01$; Fig. 3D) as demonstrated by the MTT assay following transfection with miR-15a-5p mimic at 24, 48 and 72 h compared with those transfected with $\mathrm{NC}$, respectively. The results demonstrated that miR-15a-5p may promote cell proliferation in RCC.

miR-15a-5p promoted $R C C$ cell mobility. To investigate the effect of miR-15a-5p on cell mobility in RCC cell lines (786-O and $\mathrm{ACHN}$ ), a Transwell assay and wound scratch assay were performed. As presented in Fig. 4, the results of wound scratch assay of 786-O indicated that the migratory distance of cells transfected with miR-15a-5p inhibitor was significantly reduced by $56.27 \%(\mathrm{P}<0.01)$ and $43.17 \%(\mathrm{P}<0.01)$ at 12 and 24 h compared with cells transfected with inhibitor NC (Fig. 4B). By contrast, upregulation of miR-15a-5p by transfecting miR-15a-5p mimics promoted migratory distances by $64.46 \%(\mathrm{P}<0.01)$ and $38.63 \%(\mathrm{P}<0.05)$ in $786-\mathrm{O}$ at 12 and 24 h compared cells transfected with NC (Fig. 4C). In ACHN cells (presented in Fig. 5), the downregulation of miR-15a-5p reduced the migratory distance by $30.09 \%(\mathrm{P}<0.01)$ and $22.16 \%(\mathrm{P}<0.01)$ at 12 and $24 \mathrm{~h}$ (Fig. 5B). By contrast, upregulation of miR-15a-5p promoted migratory distances by $19.94 \%$ $(\mathrm{P}<0.01)$ and $30.14 \%(\mathrm{P}<0.01)$ in ACHN cells at 12 and $24 \mathrm{~h}$ (Fig. 5C). 
A

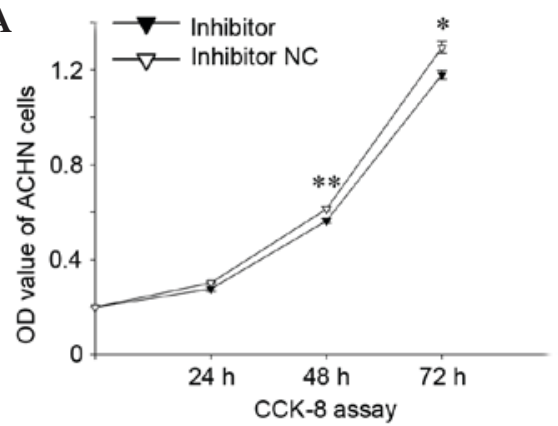

C

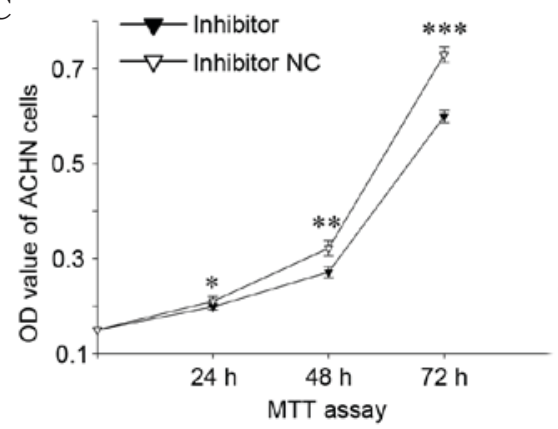

B

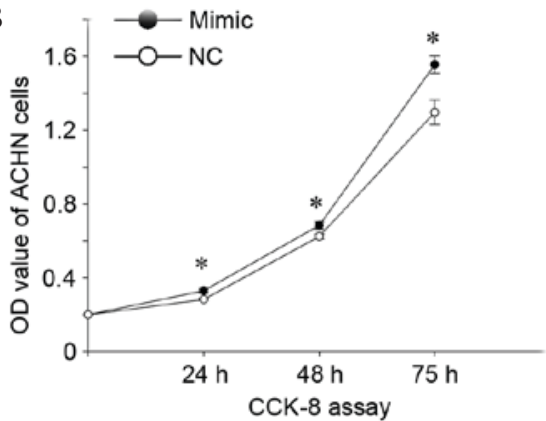

D

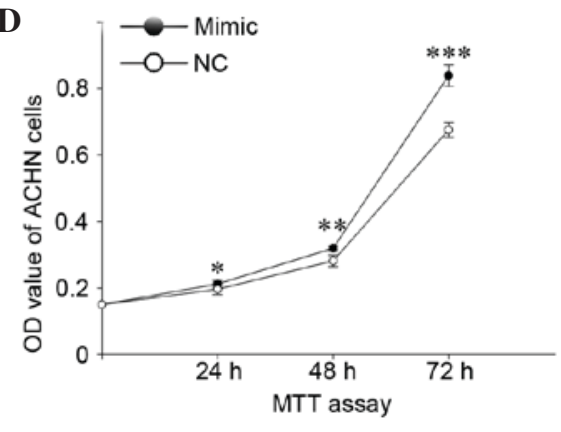

Figure 3. Cell proliferation assay of ACHN cells. (A and B) CCK-8 assay and (C and D) MTT assay were used to measure cell proliferation of ACHN cells transfected with (A and C) miR-15a-5p inhibitor or inhibitor NC and (B and D) miR-15a-5p mimic or NC was measured by CCK-8 and MTT assay. ${ }^{*} \mathrm{P}<0.05$ vs. NC, ${ }^{* *} \mathrm{P}<0.01,{ }^{* * *} \mathrm{P}<0.001$. CCK-8, Cell Counting Kit-8; miR, microRNA; NC, negative control.

A

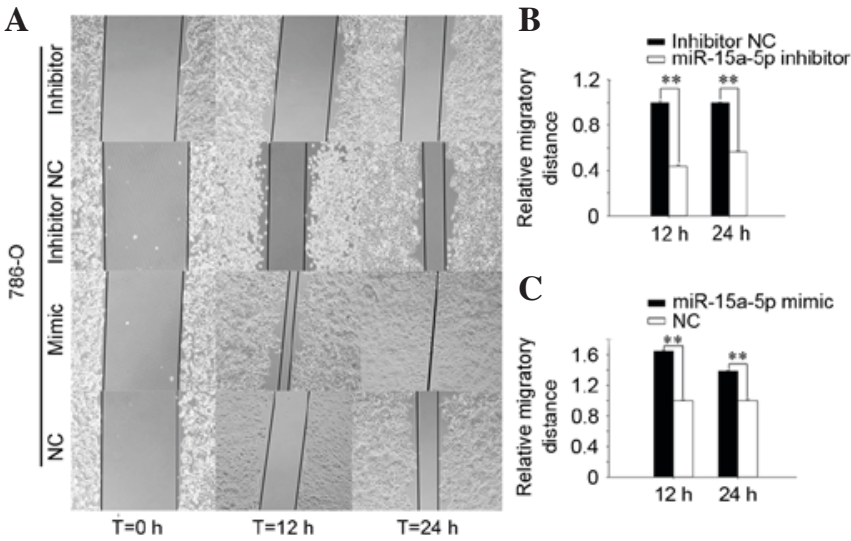

Figure 4. Wound scratch assay of 786-O cells. (A) Images captured of cell migration. x100 magnification. (B) Cell migratory distances of 786-O cells following transfection of miR-15a-5p inhibitor or inhibitor NC. (C) Cell migratory distances following transfection of miR-15a-5p mimic or NC. ${ }^{*} \mathrm{P}<0.05,{ }^{* *} \mathrm{P}<0.01,{ }^{* * *} \mathrm{P}<0.001$. miR, microRNA; NC, negative control.

The results of the Transwell assay were presented in Fig. 6. The results of the Transwell invasion assay indicated that the invasive ability of 786-O cells was significantly reduced by $66.70 \%(\mathrm{P}<0.05)$ in the miR-15a-5p inhibitor group and upregulated by $113.70 \%(\mathrm{P}<0.01)$ in the miR-15a-5p mimic group (Fig. 6B), and in ACHN cells invasive ability was reduced by $77.23 \%(\mathrm{P}<0.001)$ and upregulated by $38.24 \%(\mathrm{P}<0.01)$ in miR-15a-5p mimic group (Fig. 6C).

As presented in Fig. 6D, the migratory ability of 786-O cells transfected with miR-15a-5p inhibitors was reduced significantly by $37.79 \%(\mathrm{P}<0.01)$ and in miR-15a-5p mimic group was increased by $30.75 \%(\mathrm{P}<0.01)$. In ACHN cells the migratory ability was reduced by $62.39 \%(\mathrm{P}<0.01)$ in
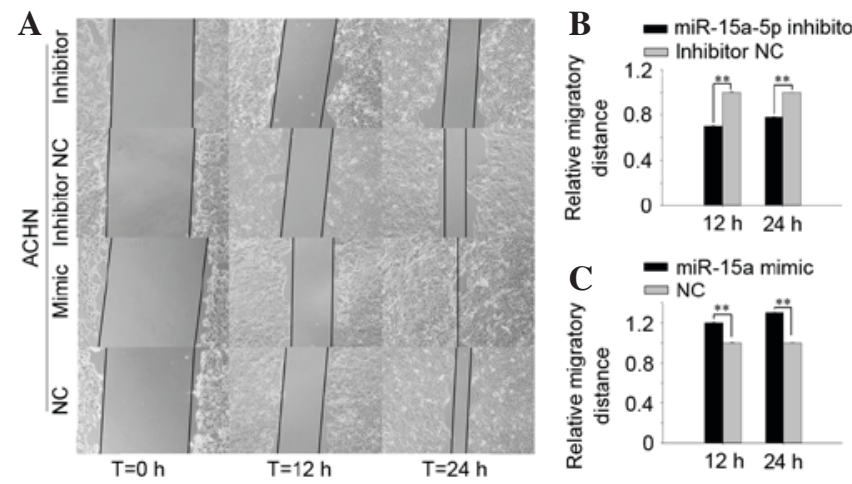

Figure 5. Wound scratch assay of ACHN cells. (A) Images captured of cell migration. x100 magnification. (B) Cell migratory distances of ACHN cells following transfection of miR-15a-5p inhibitor or inhibitor NC. (C) Cell migratory distances following transfection with miR-15a-5p mimic or NC. ${ }^{*} \mathrm{P}<0.05,{ }^{* *} \mathrm{P}<0.01,{ }^{* * *} \mathrm{P}<0.001$. miR, microRNA; NC, negative control.

miR-15a-5p inhibitor group and promoted by $85.99 \%(\mathrm{P}<0.01)$ in miR-15a-5p mimic group (Fig. 6E). The results indicated that miR-15a-5p promoted the ability of RCC cell mobility.

Downregulation of miR-15a-5p induced cell apoptosis. Apoptotic rate was determined by flow cytometry (Fig. 7) and Hoechst 33342 staining. The results indicated that downregulation of miR-15a-5p induced apoptosis of RCC cells. At $48 \mathrm{~h}$ after transfection of miR-15a-5p inhibitor or inhibitor NC, all the cells in a well were collected for measurement of apoptosis. The results demonstrated that the early apoptotic rate of 786-O cells transfected with miR-15a-5p inhibitor or inhibitor $\mathrm{NC}$ was $14.01 \pm 0.81$ vs. $2.47 \pm 0.28 \%(\mathrm{P}<0.05$; Fig. $7 \mathrm{~B})$ and the apoptotic rate of $\mathrm{ACHN}$ cells was $20.30 \pm 0.47$ vs. $11.45 \pm 0.61 \%(\mathrm{P}<0.05$; 
A
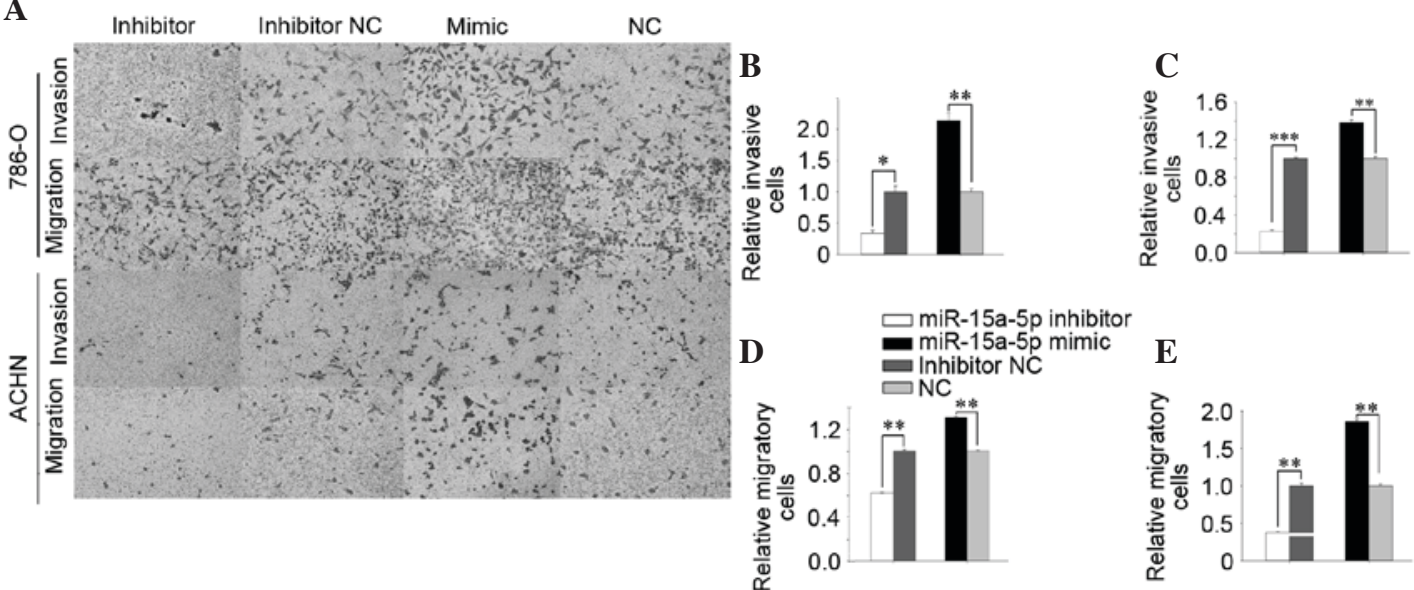

Figure 6. miR-15a-5p inhibits cell migration and invasion. (A) Images captured of invasion and migration. Relative (B and C) invasive cells and (D and E) migratory cells were quantified. x100 magnification. (B and D) MiR-15a-5p inhibited migration and invasion abilities of 786-O cells. (C and E) Similar results can be observed in ACHN cells. ${ }^{*} \mathrm{P}<0.05,{ }^{* *} \mathrm{P}<0.01,{ }^{* * *} \mathrm{P}<0.001$. miR, microRNA; NC, negative control.
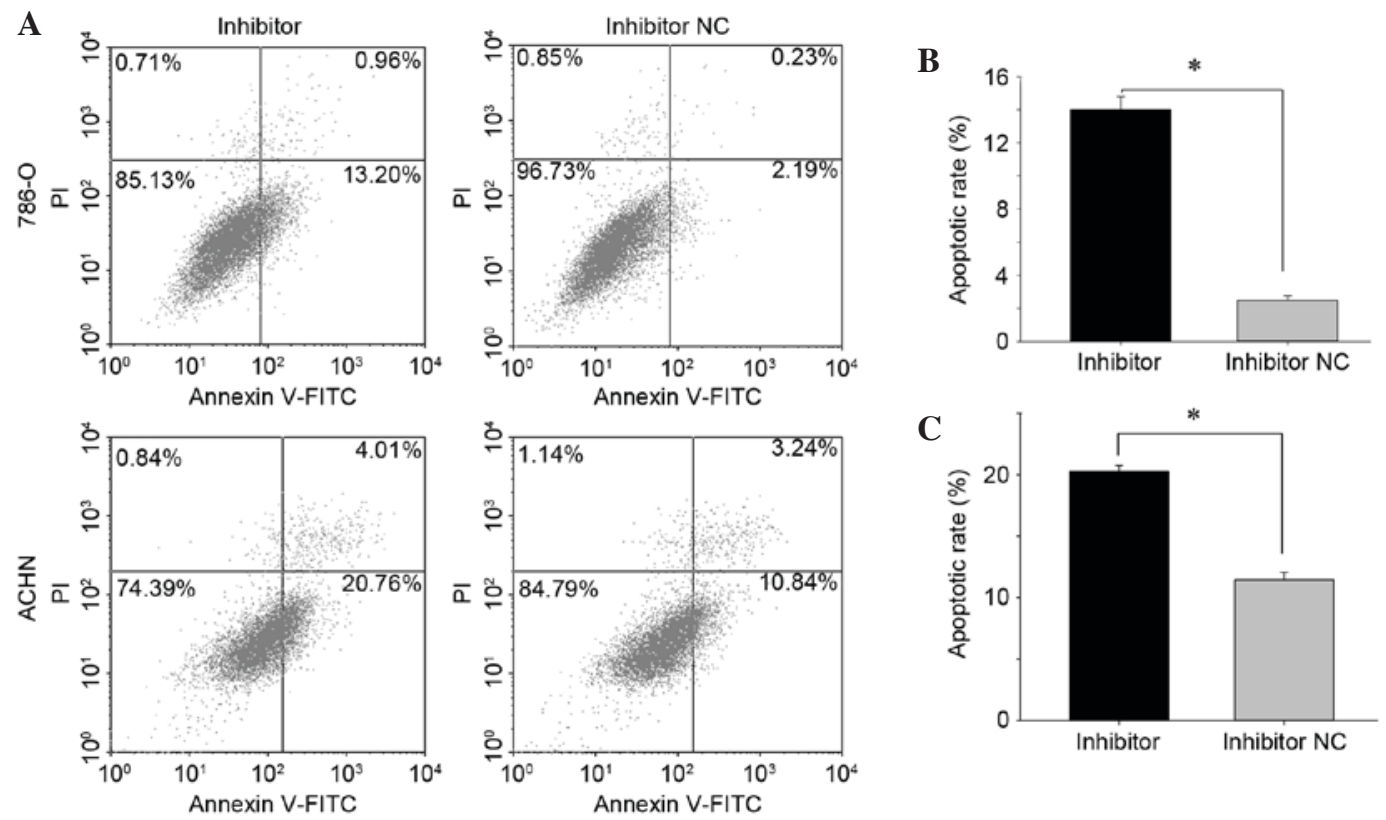

Figure 7. (A) Flow cytometry results. Cell apoptosis rate (\%) of (B) 786-O and (C) ACHN cells transfected with miR-15a-5p inhibitor or inhibitor NC. "P<0.05, ${ }^{* *} \mathrm{P}<0.01,{ }^{* * * *} \mathrm{P}<0.001$. NC, negative control; miR, microRNA; FITC, fluorescein isothiocyanate.

Fig. 7C). There was no difference observed between the mimic and $\mathrm{NC}$ group for apoptotic rates in the two groups (data not shown). The apoptotic ratio in RCC cell lines was also measured by Hoechst 33342 staining. As presented in Fig. 8, the apoptotic rate of $786-\mathrm{O}$ cells in the inhibitor group was $27.16 \pm 1.75 \%$, with $10.39 \pm 0.78 \%$ in the inhibitor $\mathrm{NC}$ group $(\mathrm{P}<0.01 ; \mathrm{Fig} .8 \mathrm{~A})$. In the $\mathrm{ACHN}$ cells the apoptotic rate in the inhibitor group or inhibitor NC group was $21.4 \pm 0.69$ vs. $11.08 \pm 0.74 \%$ (Fig. $8 \mathrm{~B} ; \mathrm{P}<0.01$ ). The results indicated that downregulation of miR-15a-5p induced cell apoptosis in RCC.

\section{Discussion}

Tumorigenesis is a complicated process associated with activation of various oncogenes or dysfunction of tumor
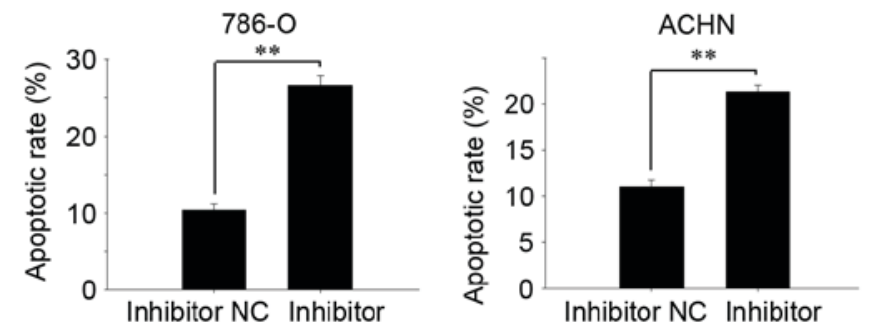

Figure 8. Cell apoptotic rate was also detected by Hochest 33342 staining. ${ }^{*} \mathrm{P}<0.05,{ }^{* *} \mathrm{P}<0.01,{ }^{* * *} \mathrm{P}<0.001$. NC, negative control.

suppressor genes. miRNAs were described as important in the pathogenesis of a number of types of cancer $(18,19)$. Mammalian miRNAs were reported to have the potential to 
regulate at least $20-30 \%$ of all genes (20), which suggested that miRNAs are important in oncogenesis and development of cancer.

Previous studies demonstrated that miR-15a-5p was downregulated in types of cancer, including prostate cancer (21), non-small-cell lung cancer (NSCLC) (22), chronic lymphocytic leukemia (23) and pancreatic cancer (14). Previous studies described the signaling pathways of miR-15a-5p in certain types of tumor (21-23). However, miR-15a-5p was observed to be upregulated in RCC tissues compared with paired normal tissues, which indicated that the underlying mechanism of miR-15a-5p in RCC is different compared with other tumors. In NSCLC, miR-15a-5p was demonstrated to induce cell apoptosis and inhibit metastasis by regulating BCL-2 like protein 2 (2). Xin et al (24) demonstrated that miR-15a-5p promoted neuroblastoma migration by targeting reversion-inducing cysteine-rich protein with Kazal motifs and regulating matrix metalloproteinase-9 expression (24). In a previous study, miR-15a-5p was observed to suppress cell viability by regulating Wnt family member $3 \mathrm{~A}$ and fibroblast growth factor 7 in pancreatic cancer (14). In another previous study about pancreatic ductal adenocarcinoma, miR-15a-5p was observed to inhibit cell proliferation and epithelial-to-mesenchymal transition by downregulating polycomb complex protein BMI-1 (6). In addition, miR-15a-5p was also reported to be downregulated in breast cancer and could affect cell processes by targeting cyclin E1 (CCNE1) (25). Li et al (26) also described synuclein- $\gamma$ as a target of miR-15a-5p in breast cancer (26). In osteosarcoma cells, miR-15a-5p was reported to regulate cell processes by targeting TNF- $\alpha$-induced protein 1 (27). Komabayashi et al (4) demonstrated that LAMP1 downregulated miR-15a-5p in nasal natural killer/T-cell lymphoma. In all these types of cancer, restoring the level of miR-15a-5p induces cell apoptosis or inhibits cell proliferation or invasion.

The miR-15 family includes miR-15a-5p, miR-15b and miR-16-1 (previously termed miR-16). As miR-15a-5p and miR-16-1 are located in the same region of chromosome $13 q 14$ (13), a number of studies have investigated the role of miR-15a-5p/16 in tumors. Our previous study determined miR-16 was upregulated in RCC tissues and acts as an oncogene (28). In addition, miR-15a-5p/16 was demonstrated to inhibit NSCLC cell progression by targeting Cripto (29). Lan et al (30) also demonstrated that miR-15a-5p/16 enhances radiation sensitivity of NSCLC cells by targeting the Toll-like receptor $1 /$ nuclear factor- $\kappa \mathrm{B}$ signaling pathway (30). In other previous studies, CCNE1 (20), Wilms tumor protein 1 (31) and vascular endothelial growth factor (32) are targets of miR-15a-5p and miR-16. miR-15a-5p/16 were also described as tumor suppressors in the types of cancer mentioned.

A previous study has demonstrated that the upregulated miR-15a-5p inversely correlated to protein kinase $\mathrm{C} \alpha$ $(\mathrm{PKC} \alpha)$ in RCC (33), however, the function of miR-15a-5p in RCC remains to be elucidated. In the present study, it was demonstrated that upregulation of miR-15a-5p promoted cell proliferation, migration and invasion in 786-O and ACHN cells. Conversely, downregulation of miR-15a-5p induced cell apoptosis and inhibited cell proliferation, migration and invasion in 786-O and ACHN cells. The results indicated that miR-15a-5p acts as an oncogene in RCC, which is different from the role of miR-15a-5p in other types of cancer.
Similarly, miR-15a-5p-3p was also described as an oncogene that may contribute to colorectal adenoma-to-carcinoma progression (34).

In addition to being involved in cancer, miR-15a-5p was also reported to regulate angiogenesis. Spinetti et al (35) reported that miR-15a-5p was increased in the proangiogenic cells (PAC) and serum of patients with critical limb ischemia, and impaired the function of the circulating human PACs (35). miR-15a-5p was described as a direct transcriptional target of Kruppel-like factor 4, which mediates its anti-proliferative and anti-angiogenic effects (36).

Previous studies have also reported that miR-15a-5p could be used as a biomarker for diagnosis and estimation of prognosis. A high level of miR-15a-5p has been associated with poor prognosis in multiple myeloma (37). For breast cancer and colorectal cancer patients low expression levels of miR-15a-5p in the primary tumor predicted a poor prognosis $(9,38)$. In addition, in triple-negative patients a low level of miR-15a-5p expression was significantly associated with shorter disease-free survival and overall survival (38). There is also a research indicating that miR-15a-5p is also a potential biomarker to differentiate between benign and malignant renal tumors in biopsy and urine samples (33). Thus, suggesting miR-15a-5p is involved in RCC cellular processes, and PKC $\alpha$ is a target of miR-15a-5p in RCC. Future research should focus on the role of miR-15a-5p as a biomarker for use in clinical situations.

In conclusion, the results of the present study demonstrated that miR-15a-5p was involved in cellular proliferation, migration, invasion and apoptosis in renal cancer cell lines, which indicated that miR-15a-5p is important in RCC. Furthermore, the results suggested that $\mathrm{miR}-15 \mathrm{a}-5 \mathrm{p}$ may be used as a therapeutic target for renal cancer treatment in the future.

\section{Acknowledgements}

The present study was supported by the National Natural Science Foundation of China (grant no. 81101922), the Science and Technology Development Fund Project of Shenzhen (grant nos. JCYJ20130402114702124, JCYJ20150403091443304 and JCYJ20150403091443329) and the Fund of Guangdong Key Medical Subject.

\section{References}

1. Chen D, Li Y, Yu Z, Li Y, Su Z, Ni L, Yang S, Gui Y and Lai Y: Downregulated microRNA-510-5p acts as a tumor suppressor in renal cell carcinoma. Mol Med Rep 12: 3061-3066, 2015.

2. Yang T, Thakur A, Chen T, Yang L, Lei G, Liang Y, Zhang S, Ren $\mathrm{H}$ and Chen M: MicroRNA-15a induces cell apoptosis and inhibits metastasis by targeting BCL2L2 in non-small cell lung cancer. Tumour Biol 36: 4357-4365, 2015.

3. Su Z, Chen D, Zhang E, Li Y, Yu Z, Shi M, Jiang Z, Ni L, Yang S, Gui Y, et al: MicroRNA-509-3p inhibits cancer cell proliferation and migration by targeting the mitogen-activated protein kinase kinase kinase 8 oncogene in renal cell carcinoma. Mol Med Rep 12: 1535-1543, 2015.

4. Komabayashi Y, Kishibe K, Nagato T, Ueda S, Takahara M and Harabuchi Y: Downregulation of miR-15a due to LMP1 promotes cell proliferation and predicts poor prognosis in nasal NK/T-cell lymphoma. Am J Hematol 89: 25-33, 2014.

5. Wang BS, Liu Z, Xu WX and Sun SL: Functional polymorphisms in microRNAs and susceptibility to liver cancer: a meta-analysis and meta-regression, Genetics and molecular research : GMR 13: $5426-5440,2014$ 
6. Guo S, Xu X, Tang Y, Zhang C, Li J, Ouyang Y, Ju J, Bie P and Wang H: miR-15a inhibits cell proliferation and epithelial to mesenchymal transition in pancreatic ductal adenocarcinoma by down-regulating Bmi-1 expression. Cancer Lett 344: 40-46, 2014.

7. Zitman-Gal T, Green J, Pasmanik-Chor M, Golan E, Bernheim J and Benchetrit S: Vitamin D manipulates miR-181c, miR-20b and miR-15a in human umbilical vein endothelial cells exposed to a diabetic-like environment. Cardiovasc Diabetol 13: 8, 2014.

8. Matsushita R, Seki N, Chiyomaru T, Inoguchi S, Ishihara T, Goto Y, Nishikawa R, Mataki H, Tatarano S, Itesako T, et al.: Tumour-suppressive microRNA-144-5p directly targets CCNE1/2 as potential prognostic markers in bladder cancer, British journal of cancer,2015.

9. Xiao G, Tang H, Wei W, Li J, Ji L and Ge J: Aberrant expression of MicroRNA-15a and MicroRNA-16 synergistically associates with tumor progression and prognosis in patients with colorectal cancer. Gastroenterol Res Pract 2014: 364549, 2014.

10. Rasmussen F: Metastatic renal cell cancer. Cancer Imaging 13: 374-380, 2013.

11. Patel C, Ahmed A and Ellsworth P: Renal cell carcinoma: A reappraisal. Urol Nurs 32: 182-190; quiz 191, 2012.

12. Alt AL, Boorjian SA, Lohse CM, Costello BA, Leibovich BC and Blute ML: Survival after complete surgical resection of multiple metastases from renal cell carcinoma. Cancer 117: 2873-2882, 2011.

13. Bottoni A, Piccin D, Tagliati F, Luchin A, Zatelli MC and degli Uberti EC: miR-15a and miR-16-1 down-regulation in pituitary adenomas. J Cell Physiol 204: 280-285, 2005.

14. Zhang XJ, Ye H, Zeng CW, He B, Zhang $\mathrm{H}$ and Chen YQ: Dysregulation of miR-15a and miR-214 in human pancreatic cancer. J Hematol Oncol 3: 46, 2010.

15. Humplikova L, Kollinerova S, Papajik T, Pikalova Z, Holzerova M, Prochazka V, Divoka M, Modriansky M, Indrak K and Jarosova M: Expression of miR-15a and miR-16-1 in patients with chronic lymphocytic leukemia. Biomed Pap Med Fac Univ Palacky Olomouc Czech Repub 157: 284-293, 2013.

16. Renjie W and Haiqian L: MiR-132, miR-15a and miR-16 synergistically inhibit pituitary tumor cell proliferation, invasion and migration by targeting Sox 5. Cancer Lett 356: 568-578, 2015

17. Livak KJ and Schmittgen TD: Analysis of relative gene expression data using real-time quantitative PCR and the 2(-Delta Delta C(T)) method. Methods 25: 402-408, 2001.

18. Bhattacharya R, Nicoloso M, Arvizo R, Wang E, Cortez A Rossi S, Calin GA and Mukherjee P: MiR-15a and MiR-16 control Bmi-1 expression in ovarian cancer. Cancer Res 69: 9090-9095, 2009.

19. Satzger I, Mattern A, Kuettler U, Weinspach D, Voelker B, Kapp A and Gutzmer R: MicroRNA-15b represents an independent prognostic parameter and is correlated with tumor cell proliferation and apoptosis in malignant melanoma. Int J Cancer 126: 2553-2562, 2010.

20. Ofir M, Hacohen D and Ginsberg D: MiR-15 and miR-16 are direct transcriptional targets of E2F1 that limit E2F-induced proliferation by targeting cyclin E. Mol Cancer Res 9: 440-447, 2011.

21. Musumeci M, Coppola V, Addario A, Patrizii M, Maugeri-Saccà M, Memeo L, Colarossi C, Francescangeli F, Biffoni M, Collura D, et al: Control of tumor and microenvironment cross-talk by miR-15a and miR-16 in prostate cancer. Oncogene 30: 4231-4242, 2011.

22. Bandi N, Zbinden S, Gugger M, Arnold M, Kocher V, Hasan L, Kappeler A, Brunner T and Vassella E: miR-15a and miR-16 are implicated in cell cycle regulation in a Rb-dependent manner and are frequently deleted or down-regulated in non-small cell lung cancer. Cancer Res 69: 5553-5559, 2009.
23. Hanlon K, Rudin CE and Harries LW: Investigating the targets of MIR-15a and MIR-16-1 in patients with chronic lymphocytic leukemia (CLL). PLoS One 4: e7169, 2009.

24. Xin C, Buhe B, Hongting L, Chuanmin Y, Xiwei H, Hong Z, Lulu H, Qian D and Renjie W: MicroRNA-15a promotes neuroblastoma migration by targeting reversion-inducing cysteine-rich protein with Kazal motifs (RECK) and regulating matrix metalloproteinase-9 expression. FEBS J 280: 855-866, 2013.

25. Luo Q, Li X, Li J, Kong X, Zhang J, Chen L, Huang Y and Fang L: MiR-15a is underexpressed and inhibits the cell cycle by targeting CCNE1 in breast cancer. Int J Oncol 43: 1212-1218, 2013.

26. Li P, Xie XB, Chen Q, Pang GL, Luo W, Tu JC, Zheng F, Liu SM, Han L, Zhang JK, et al: MiRNA-15a mediates cell cycle arrest and potentiates apoptosis in breast cancer cells by targeting synuclein- $\gamma$. Asian Pac J Cancer Prev 15: 6949-6954, 2014

27. Tian X, Zhang J, Yan L, Dong JM and Guo Q: MiRNA-15a inhibits proliferation, migration and invasion by targeting TNFAIP1 in human osteosarcoma cells. Int J Clin Exp Pathol 8: 6442-6449, 2015.

28. Chen D, Li Y, Yu Z, Su Z, Yu W, Li Y, Yang S, Gui Y, Ni L and Lai Y: Upregulated microRNA-16 as an oncogene in renal cell carcinoma. Mol Med Rep 12: 1399-1404, 2015.

29. Chen F, Hou SK, Fan HJ and Liu YF: MiR-15a-16 represses Cripto and inhibits NSCLC cell progression. Mol Cell Biochem 391: 11-19, 2014

30. Lan F, Yue X, Ren G, Li H, Ping L, Wang Y and Xia T: miR-15a/16 enhances radiation sensitivity of non-small cell lung cancer cells by targeting the TLR1/NF- $\mathrm{KB}$ signaling pathway. Int J Radiat Oncol Biol Phys 91: 73-81, 2015.

31. Gao SM, Xing CY, Chen CQ, Lin SS, Dong PH and Yu FJ: miR-15a and miR-16-1 inhibit the proliferation of leukemic cells by down-regulating WT1 protein level. J Exp Clin Cancer Res 30: 110, 2011.

32. Sun CY, She XM, Qin Y, Chu ZB, Chen L, Ai LS, Zhang L and $\mathrm{Hu}$ Y: miR-15a and miR-16 affect the angiogenesis of multiple myeloma by targeting VEGF. Carcinogenesis 34: 426-435, 2013.

33. von Brandenstein M, Pandarakalam JJ, Kroon L, Loeser H, Herden J, Braun G, Wendland K, Dienes HP, Engelmann U and Fries JW: MicroRNA 15a, inversely correlated to PKC $\alpha$, is a potential marker to differentiate between benign and malignant renal tumors in biopsy and urine samples. Am J Pathol 180: 1787-1797, 2012

34. de Groen FL, Timmer LM, Menezes RX, Diosdado B, Hooijberg E, Meijer GA, Steenbergen RD and Carvalho B: Oncogenic role of miR-15a-3p in 13q amplicon-driven colorectal adenoma-to-carcinoma progression. PLoS One 10: e0132495, 2015.

35. Spinetti G, Fortunato O, Caporali A, Shantikumar S, Marchetti M, Meloni M, Descamps B, Floris I, Sangalli E, Vono R, et al: MicroRNA-15a and microRNA-16 impair human circulating proangiogenic cell functions and are increased in the proangiogenic cells and serum of patients with critical limb ischemia. Circ Res 112: 335-346, 2013.

36. Zheng X, Li A, Zhao L, Zhou T, Shen Q, Cui Q and Qin X: Key role of microRNA-15a in the KLF4 suppressions of proliferation and angiogenesis in endothelial and vascular smooth muscle cells. Biochem Biophys Res Commun 437: 625-631, 2013.

37. Gao X, Zhang R, Qu X, Zhao M, Zhang S, Wu H, Jianyong L and Chen L: MiR-15a, miR-16-1 and miR-17-92 cluster expression are linked to poor prognosis in multiple myeloma. Leuk Res 36: 1505-1509, 2012.

38. Shinden Y, Akiyoshi S, Ueo H, Nambara S, Saito T, Komatsu H, Ueda M, Hirata H, Sakimura S, Uchi R, et al: Diminished expression of MiR-15a is an independent prognostic marker for breast cancer cases. Anticancer Res 35: 123-127, 2015. 